\title{
Synaptic and cellular profile of neurons in the lateral habenula
}

\author{
Frank J. Meye ${ }^{1,2,3}$, Salvatore Lecca ${ }^{1,2,3}$, Kristina Valentinova ${ }^{1,2,3}$ and Manuel Mameli ${ }^{1,2,3}$ * \\ 1 Institut du Fer à Moulin, Paris, France \\ 2 INSERM, UMR-S 839, Paris, France \\ ${ }^{3}$ Université Pierre et Marie Curie, Paris, France
}

Edited by:

Ramiro Salas, Baylor College of

Medicine, USA

\section{Reviewed by:}

Hidenori Aizawa, Tokyo Medical and

Dental University, Japan

Carl R. Lupica, National Institutes of

Health, National Institute on Drug

Abuse, USA

\section{${ }^{*}$ Correspondence:}

Manuel Mameli, Institut du Fer à

Moulin, UMRS-S 839, INSERM, 17

Rue du Fer à Moulin, 75005 Paris,

France

e-mail: manuel.mameli@inserm.fr
The lateral habenula $(\mathrm{LHb})$ is emerging as a crucial structure capable of conveying rewarding and aversive information. Recent evidence indicates that a rapid increase in the activity of LHb neurons drives negative states and avoidance. Furthermore, the hyperexcitability of neurons in the LHb, especially those projecting to the midbrain, may represent an important cellular correlate for neuropsychiatric disorders like depression and drug addiction. Despite the recent insights regarding the implications of the $\mathrm{LHb}$ in the context of reward and aversion, the exact nature of the synaptic and cellular players regulating LHb neuronal functions remains largely unknown. Here we focus on the synaptic and cellular physiology of LHb neurons. First, we discuss the properties of excitatory transmission and the implications of glutamate receptors for long-term synaptic plasticity; second, we review the features of GABAergic transmission onto LHb neurons; and finally, we describe the contribution that neuromodulators such as dopamine (DA) and serotonin may have for $\mathrm{LHb}$ neuronal physiology. We relate these findings to the role that the LHb can play in processing aversive and rewarding stimuli, both in health and disease states.

Keywords: lateral habenula, synaptic transmission, AMPA receptors, GABA receptors, neuromodulators

\section{INTRODUCTION}

Significant evidence is converging to the idea that the lateral habenula $(\mathrm{LHb})$ strongly controls midbrain targets including the ventral tegmental area (VTA), substantia nigra pars compacta and the raphe nuclei (Christoph et al., 1986; Hikosaka, 2010). Functionally, the LHb contributes to the encoding of aversion and reward, and also plays a role in associated pathological conditions such as mood disorders and drug addiction (Hikosaka, 2010). A comprehensive understanding of $\mathrm{LHb}$ functions and their implications in neuropsychiatric disorders requires the dissection of the cellular and synaptic properties of neurons in this nucleus. Here, we describe how LHb neurons activity can be influenced by excitatory and inhibitory synapses and by neuromodulators, and we discuss the significance of this in relation to the potential role of the LHb in encoding rewarding and aversive stimuli, and in associated psychiatric disorders.

\section{THE LATERAL HABENULA (LHb): A HIGHWAY TO THE MIDBRAIN FOR PROCESSING AVERSION AND REWARD ANATOMICAL AND MORPHOLOGICAL ORGANIZATION}

The LHb, together with the medial habenula $(\mathrm{MHb})$, is part of the epithalamus, and located above the thalamus at its posterior end close to the midline. The LHb comprises a medial and a lateral division (Andres et al., 1999; Hikosaka, 2010). LHb neurons present a dendritic arborization with postsynaptic spines (Figure 1; Weiss and Veh et al., 2011; Maroteaux and Mameli, 2012). Morphological and immunohistochemical studies revealed heterogeneous populations randomly distributed throughout the LHb based on somatodendritic organization and receptor expression (Weiss and Veh et al., 2011; Aizawa et al., 2012).

The main output of the LHb is glutamatergic (Li et al., 2011; Aizawa et al., 2012; Lammel et al., 2012; Stamatakis and Stuber, 2012). Axons from the LHb descend through the fasciculus retroflexus to deep structures: to GABAergic and dopaminergic neurons in the VTA, to GABAergic and serotoninergic neurons in the dorsal and median raphe, and to GABAergic neurons in the rostromedial tegmental nucleus (RMTg or tail-VTA; Herkenham and Nauta, 1979; Jhou et al., 2009; Barrot et al., 2012). However, single cell morphology studies also indicate that some LHb neurons can project to neighboring neurons within the LHb (Weiss and Veh et al., 2011), suggesting an internal control within the structure.

\section{LHb IN AVERSION AND REWARD}

The LHb is pivotal in processing aversive and rewarding information. Delivery of an unexpected airpuff, a cue that predicts its onset, or even the omission of an expected reward, leads to a strong increase in the activity of LHb neurons in monkeys. Conversely, unexpected delivery of rewards and cues predicting a reward decrease LHb neuron firing. The LHb is inhibited more strongly as expected reward probability or magnitude increase (Matsumoto and Hikosaka, 2007, 2009). Importantly, the activity 


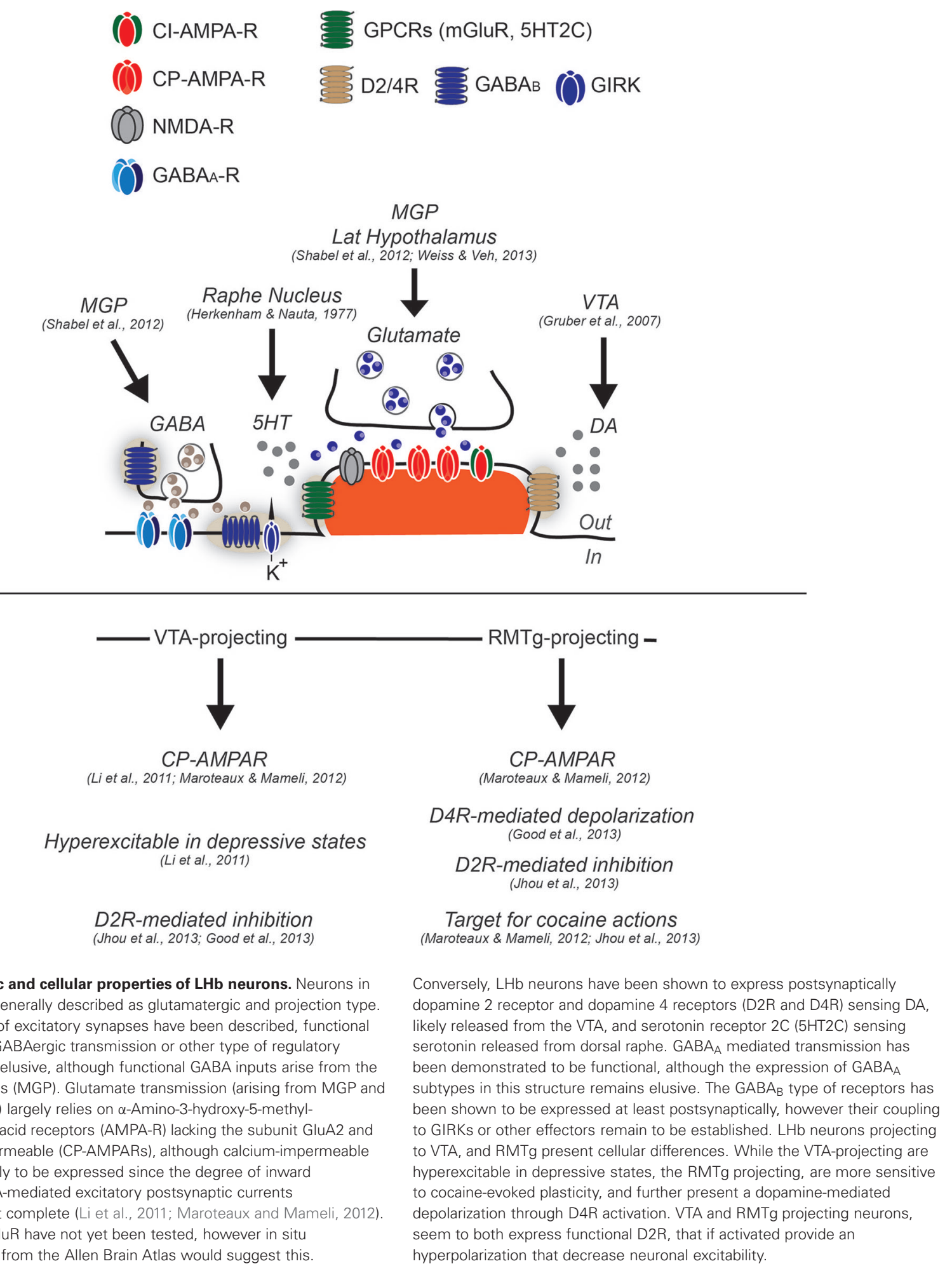

in LHb neurons is the inverse of that of dopamine (DA) neurons in the midbrain during aversive and rewarding states. The punishment-driven increase in excitation of LHb occurs earlier than that of DA neurons, suggesting the upstream control of the LHb on the DA system. This may not be reflected in the case of reward delivery, leaving the causality of this relationship still as an open question (Matsumoto and Hikosaka, 2007). Together these findings suggest that LHb neurons code for discrepancies between reward or punishment-related expectation and outcome. 
Recent advances have shed light on the implication of LHb in driving aversive behaviors. Indeed, optogenetic activation of excitatory projection to the $\mathrm{LHb}$, and $\mathrm{LHb}$ terminals in the midbrain drives aversive behaviors (Lammel et al., 2012; Shabel et al., 2012; Stamatakis and Stuber, 2012). However, while such evidence identified a crucial role of $\mathrm{LHb}$ in driving motivation, a precise dissection of synaptic and cellular properties within the $\mathrm{LHb}$ remains elusive and necessary to globally understand the role of this structure for specific behaviors.

\section{SYNAPTIC TRANSMISSION IN THE LATERAL HABENULA (LHb) EXCITATORY TRANSMISSION IN THE LATERAL HABENULA (LHb)}

$\mathrm{LHb}$ neurons receive glutamatergic projections from various structures that include the MGP, as well as the lateral hypothalamus, the cortex and likely the VTA (Weiss and Veh et al., 2011; Hnasko et al., 2012; Shabel et al., 2012). Below, we will discuss the postsynaptic receptors that mediate excitatory transmission onto LHb neurons and their role in long-term and experiencedependent synaptic plasticity.

\section{Glutamate receptors}

The predominant receptor in the $\mathrm{LHb}$ mediating fast excitatory transmission is the AMPA-type glutamate receptor (AMPAR): a heterotetrameric complex highly sensitive to experience-driven changes (Hollmann et al., 1994). The AMPA GluA2 subunit is edited at the mRNA level (glutamine to arginine) (Lomeli et al., 1994) conferring channel impermeability to calcium. AMPARs lacking the subunit GluA2 are instead calcium permeable (CPAMPARs), and exhibit inward rectification due to voltagedependent block of the receptor by intracellular polyamines at positive potentials (Burnashev et al., 1992; Donevan and Rogawski, 1995). Patch-clamp recordings in rats and mice from $\mathrm{LHb}$ neurons indicate that the AMPA-mediated currents are inwardly rectifying, suggesting that glutamatergic input to the $\mathrm{LHb}$ relies, at least to a significant extent, on CP-AMPARs (Figure 1; Li et al., 2011; Maroteaux and Mameli, 2012). CPAMPAR expression is a general feature of $\mathrm{LHb}$ neurons, as projection-specific retrograde labeling demonstrated that the rectification index, a measure reflecting the presence of GluA2lacking AMPARs, did not differ between LHb subpopulations (Figure 1; Li et al., 2011; Maroteaux and Mameli, 2012).

Metabotropic glutamate receptors (mGluRs) generally strongly modulate CP-AMPAR expression. Indeed, mGluRs trigger long-term depression (LTD) of AMPAR currents specifically when CP-AMPARs are present (Luscher and Huber, 2010). In several structures including the VTA, the nucleus accumbens and the cerebellum, mGluR activation triggers a switch from CP-AMPARs to calcium impermeable AMPARs. mGluRs evoke CP-AMPAR internalization, regulate experience-induced synaptic plasticity, and in some cases restore experience-driven adaptations (Bellone and Luscher, 2006; Kelly et al., 2009; Clem and Huganir, 2010; McCutcheon et al., 2011). mGluRs are also expressed in the LHb, although seemingly at relatively low levels (Figure 1). However, the function of mGluRs in the LHb and their relationship with the CP-AMPARs in this structure remains unknown.
Interestingly, the NMDA-mediated component at $\mathrm{LHb}$ synapses at positive potentials is small compared to the one mediated by AMPA receptors, indicative for a low expression of synaptic N-methyl-d-aspartate receptors (NMDAR; Li et al., 2011; Maroteaux and Mameli, 2012). Whether NMDARs are or not expressed at excitatory synapses, or whether their expression is limited to extrasynaptic sites remains to be established. Further insight in their subunit composition, and their potential role in long-term synaptic plasticity also still needs to be addressed.

\section{Synaptic plasticity in the $\mathbf{L H b}$}

CP-AMPARs regulate the induction of several forms of longterm synaptic plasticity (Kullmann and Lamsa, 2011). In the VTA, CP-AMPAR expression, triggered by acute cocaine exposure (Bellone and Luscher, 2006), allows the expression of a CPAMPAR-dependent long-term potentiation (LTP) that relies on postsynaptic hyperpolarization (Mameli et al., 2011). Such a CPAMPAR-dependent LTP, relying on postsynaptic hyperpolarization, has also been described for interneurons of the hippocampus (Lamsa et al., 2007; Le Roux et al., 2013). Whether CP-AMPARs also drive long-term plasticity in the $\mathrm{LHb}$ has been recently explored. Stimulation of excitatory presynaptic terminals paired with postsynaptic hyperpolarization leads to an LTD of AMPAR currents (Maroteaux and Mameli, 2012). Interestingly, exposure to cocaine for 2 consecutive days strengthens CP-AMPAR transmission onto $\mathrm{LHb}$ neurons that project to the RMTg, but not onto those that project to the VTA. Moreover, the cocaine exposure switches the direction of long-term plasticity from LTD to LTP in these RMTg-projecting neurons. It remains to be elucidated whether and how these LHb neurons can be hyperpolarized in physiological conditions to allow CP-AMPARs to be efficient. Interestingly, stimulation of the main fiber bundle converging to the $\mathrm{LHb}$ (i.e., the stria medullaris) drives a strong hyperpolarization that reduces neuronal activity representing an ideal state for CP-AMPAR activation (Chang and Kim, 2004). The receptors mediating an hyperpolarizing state may be several, and below we will discuss the potential implication of some of them including $\mathrm{GABA}_{\mathrm{A}} \mathrm{Rs}, \mathrm{GABA}_{\mathrm{B}} \mathrm{Rs}$, and D2Rs. Dynamics of AMPARs in the LHb have been recently implicated in depressivelike states. Indeed, evidence suggests that Calcium-calmodulindependent protein kinase II ( $\beta$ CaMKII)-mediated trafficking of GluA1-containing AMPARs in LHb may participate in the expression of depressive-like symptoms (Li et al., 2013). Altogether these results place maladaptations of AMPAR transmission in the $\mathrm{LHb}$ as a potential cellular substrate for psychiatric disorders associated with reward or aversion.

\section{INHIBITORY TRANSMISSION IN THE LATERAL HABENULA (LHb)}

The $\mathrm{LHb}$ receives strong GABAergic innervation (Araki et al., 1984), presumably coming from long-range projections, since local interneurons are largely absent (Smith et al., 1987; Li et al., 2011). One GABAergic input arises from the MGP, and preferentially targets the lateral portion of the LHb (Shabel et al., 2012). Anatomical studies suggest that other GABAergic projections may arise from the diagonal band of broca, the lateral preoptic area, the nucleus accumbens, substantia innominata, and the ventral pallidum (Geisler and 
Trimble, 2008), although their functional properties remain unknown. Evidence suggests that GABAergic transmission in the $\mathrm{LHb}$ is mediated by both $\mathrm{GABA}_{\mathrm{A}} \mathrm{Rs}$ and $\mathrm{GABA}_{\mathrm{B}} \mathrm{Rs}$, and we will discuss their implications for LHb neuronal function.

\section{GABA $_{\boldsymbol{A}}$ receptors}

$\mathrm{GABA}_{\mathrm{A}} \mathrm{Rs}$ are pentameric ionotropic receptors, assembled out of a larger available pool of 19 subunits, which determine the conduction kinetics of the receptor as well as its affinity for GABA (Farrant and Nusser, 2005). In mice the LHb harbors mRNA (and largely also expresses the protein) for $\alpha 1-3$ (but not $\alpha 4-6$ ), $\beta 1$ (but not $\beta 2-3$ ) and $\gamma 1-2$ subunits (but not $\delta$ subunits) although unmentioned subunits were not assessed (Hortnagl et al., 2013). Another study conducted in rat tissue yielded slightly different results, indicating that $\mathrm{GABA}_{\mathrm{A}} \mathrm{Rs}$ in the LHb mainly consist of $\alpha 1, \beta 2$ and $\gamma 3$ subunits. These data are in line with a synaptic, rather than an extrasynaptic localization of $\mathrm{GABA}_{\mathrm{A}}$ Rs (Figure 1; Pirker et al., 2000; Hortnagl et al., 2013). Evidence suggests that strong inhibitory GABAergic signaling via the $\mathrm{GABA}_{\mathrm{A}}$ receptor takes place in the LHb. First, the LHb plentifully contains the potassium chloride cotransporter-2 (KCC2), the main chlorine-extrusion mechanism ensuring that $\mathrm{GABA}_{\mathrm{A}} \mathrm{R}$ signaling is inhibitory. Second, bath application of exogenous GABA in a slice preparation elicits large $G_{A B A_{A}} R$ mediated currents in LHb neurons. Finally $\mathrm{GABA}_{\mathrm{A}} \mathrm{R}$-mediated miniature inhibitory spontaneous currents were observed in the $\mathrm{LHb}$, indicating synaptic $\mathrm{GABA}_{\mathrm{A}} \mathrm{R}$-activation upon single vesicle release (Wang et al., 2006).

GABAergic signaling within the $\mathrm{LHb}$ has relevance in the context of drug intake. GABA (but not glutamate) immunolabeling decreased in the $\mathrm{LHb}$ in rats withdrawn (5 days) from chronic treatment with cocaine (Meshul et al., 1998). Prolonged cocaine withdrawal (21 days) increased binding of a radiolabeled benzodiazepine (which binds to $\mathrm{GABA}_{\mathrm{A}} \mathrm{Rs}$ ) in the whole $\mathrm{LHb}$, whereas acute withdrawal from this treatment slightly decreased binding (Keys and Ellison, 1999). Furthermore, withdrawal from amphetamine yielded bidirectional differences in GABAergic markers in the LHb, depending on drug concentration (Yin et al., 2012). These findings indicate that drastic adaptations occur in GABAergic innervation of the LHb upon psychostimulant exposure. (Keys and Ellison, 1999) suggest that diminished GABAergic transmission in the LHb may stand at the basis of neurotoxicity in the fasciculus retroflexus, leading to a loss of inhibitory control from LHb over monoaminergic systems.

\section{$\mathrm{GABA}_{B}$ receptors}

GABA transmission also relies on $\mathrm{G}_{\mathrm{i} / \mathrm{o}}$ protein-coupled $\mathrm{GABA}_{\mathrm{B}} \mathrm{Rs}$, which are responsible for slower and late inhibitory conductance (Hill, 1985). $\mathrm{GABA}_{\mathrm{B}}$ Rs assemble into heteromers composed of a $\mathrm{GABA}_{\mathrm{B}} 1$ (with distinct variants $\mathrm{GABA}_{\mathrm{B}} 1_{\mathrm{a}}$ and $\mathrm{GABA}_{\mathrm{B}} 1_{\mathrm{b}}$ ) and $\mathrm{a}$ $G_{A B A} 2$ subunit, which are required for normal receptor functioning (Marshall et al., 1999; Bettler et al., 2004). Ultrastructural studies show that $\mathrm{GABA}_{\mathrm{B}} \mathrm{R}$ subunits can generally be present both on pre- and postsynaptic sites as well as on extrasynaptic membranes (Figure 1; Lujan and Ciruela, 2012). The habenular complex (comprising both the $\mathrm{MHb}$ and $\mathrm{LHb}$ ) is among the regions with the highest expression of $\mathrm{GABA}_{\mathrm{B}}$ Rs. However, the functions of $G_{A B A} R$ s in these nuclei in both physiological and pathological conditions remain unknown (Margeta-Mitrovic et al., 1999; Liang et al., 2000). Within the habenular complex, the LHb present a fairly high expression of $\mathrm{GABA}_{\mathrm{B}} \mathrm{Rs}$, although less than in the $\mathrm{MHb}$ and no obvious differences are present in the two $\mathrm{GABA}_{\mathrm{B}} 1$ Rs variants (Liang et al., 2000).

$G_{A B A} R$ activation inhibits adenylyl cyclase and mediates the hyperpolarization of post-synaptic membranes by activation of inwardly rectifying potassium (GIRK) channels (Luscher et al., 1997). Interestingly, a moderate expression of Kir3.2 potassium channel subunit has been detected in the LHb (Geisler et al., 2003). Indeed, activation of $\mathrm{GABA}_{\mathrm{B}} \mathrm{Rs}$ by the selective agonist baclofen evoked an outward postsynaptic current in LHb neurons recorded (Wang et al., 2006) and together with immunocytochemistry evidence, this idicates the expression of functional postsynaptic $\mathrm{GABA}_{B}$ Rs in the LHb (Geisler et al., 2003). GABA $\mathrm{B}_{\mathrm{B}} \mathrm{R}$ activation controls a broad amount of neuronal properties including excitability and synaptic strength (Luscher and Slesinger, 2010). The potential role of $\mathrm{GABA}_{\mathrm{B}}$ Rs in controlling $\mathrm{LHb}$ neurons functions, especially in the context of reward and aversion and related pathologies, remains to be evaluated. Dysregulation of GABA transmission and $\mathrm{GABA}_{\mathrm{B}}$ function has been implicated in various central nervous system (CNS) disorders including anxiety, depression and addiction where the role of LHb is crucial (Hikosaka, 2010; Luscher and Slesinger, 2010).

\section{NEUROMODULATORY SYSTEMS IN THE LATERAL HABENULA (LHb) Dopamine (DA) modulation in the $\mathbf{L H b}$}

Dopaminergic nuclei such as the VTA and substantia nigra pars compacta receive input from the $\mathrm{LHb}$, and also provide feedback projections, suggesting that DA may modulate LHb activity (Phillipson and Pycock, 1982; Gruber et al., 2007). Indeed, both the local application of DA and the systemic administration of dopaminergic agonists increase firing of LHb neurons (Kowski et al., 2009). Moreover, tetanic stimulation of the VTA increases LHb neuron firing rate (Shen et al., 2012). Conversely, in vivo recordings show that in $\mathrm{LHb}$ neurons activated by a painful stimulus, the single-pulse stimulation of VTA and substantia nigra inhibits the firing of $\sim 90 \%$ of the LHb neurons (Shen et al., 2012). Together this suggests a complex role of the midbrain and DA in controlling activity of LHb neurons.

Fibers expressing tyrosine hydroxylase, the rate-limiting enzyme in the synthesis of DA, have been demonstrated in the LHb (Geisler et al., 2003; Gruber et al., 2007; Aizawa et al., 2012). D2Rs and D4Rs are also functionally expressed in this region (Aizawa et al., 2012; Good et al., 2013; Jhou et al., 2013; Figure 1). Acting on the D2Rs, both DA and DA receptor agonists induced an hyperpolarization that drives a decrease in firing frequency in LHb neurons projecting to both RMTg and VTA (Figure 1; Good et al., 2013; Jhou et al., 2013). On the other hand DA binding to D4Rs depolarizes LHb neurons that preferentially project to the RMTg (Figure 1; Good et al., 2013). Cocaine evokes an overall excitation of LHb neurons projecting to RMTg, which has been shown to contribute to aversive conditioning after the drug rewarding effects has faded out, consistent with the 
theory of opponent processes (Solomon and Corbit, 1974; Jhou et al., 2013). The cellular mechanisms underlying this late onset cocaine-evoked excitation are unknown. Altogether, this evidence suggests that DA signals from the midbrain control LHb neuronal activity, providing new insights for the behavioral relevance of this feedback connection. Moreover, two notable points must be kept in mind. First, dopaminergic innervation of the LHb may also, to a lesser extent, come from other regions than the midbrain, such as the posterior hypothalamus and the periaqueductal gray (Gruber et al., 2007). Second, midbrain nuclei may not just use DA to regulate the LHb. Indeed VTA neurons with a glutamatergic profile also innervate the whole LHb (Hnasko et al., 2012), suggesting complex regulatory feedback from the midbrain to $\mathrm{LHb}$ that needs to be explored further.

\section{HT modulation in the $\mathrm{LHb}$}

Analogously to the DA system, there is evidence that LHb neurons powerfully modulate raphe serotonin neurons, but also receive a serotoninergic feedback signal (Figure 1; Wang and Aghajanian, 1977; Mengod et al., 1990; Aizawa et al., 2012). The modulation by serotonin in the LHb neurons was recently investigated. By using optogenetic tools to input-specifically activate AMPARs at the MGP-to-LHb pathway, it was shown that serotonin bath application decreases AMPA-mediated transmission likely via a presynaptic rather than a postsynaptic mechanism (Shabel et al., 2012). These results indicate that either serotonin receptors in the $\mathrm{LHb}$ are exclusively presynaptic, or that they exert their effect through postsynaptic receptors, yet to be identified (Figure 1), and a retrograde messenger. Instead, this configuration may represent an input- or region-specific property since MGP inputs only innervate the lateral portion of the LHb (Hong and Hikosaka, 2008; Shabel et al., 2012). In this context, it is important to note that, while stimulation of the MGP-LHb pathway in behaving mice leads to avoidance behavior, the implications of the serotoninergic component in this behavior remains unknown.

\section{CONCLUDING REMARKS}

Initial evidence collected in the early 1980's pointed to the potential importance of the LHb in controlling midbrain structures. However, only much more recently it is starting to become clear that this structure participates in the encoding of aversive and rewarding stimuli, influences motivational states, and contributes to pathologies such as mood disorders and addiction. These findings highlight the importance to understand how LHb neuronal activity levels are influenced by the integration of local synaptic and neuromodulatory signals.

While we have discussed the presumably key input signals and their receptors in this review, tentative evidence suggests that other potentially relevant molecules may also act in the LHb, by mechanisms that remain largely unknown. Among these potential modulatory signals are orexins (Peyron et al., 1998), acetylcholine (Geisler et al., 2003), vasopressin (Rood et al., 2008), substance P (Yang et al., 2013), and BDNF (Liu et al., 2001). Another notable point is that $\mathrm{LHb}$ neuronal activity will also largely be dependent on a variety of important intrinsic ion channels that LHb neurons express, which were beyond the scope of the current review. For instance, $\mathrm{LHb}$ neurons projecting to the VTA and the raphe nuclei express T- and L-type calcium channels that allows for longlasting neuronal discharges as well as hyperpolarization-activated cyclic nucleotide-gated cation channels ( $\mathrm{HCN}$ ) suggesting an autonomous pacemaker activity (Chang and Kim, 2004; Poller et al., 2011).

The big challenge in this field is now to identify which synaptic and intrinsic properties adapt during or after exposure to aversion or reward; and to understand the downstream implications of such changes on monoamines like the DA and serotonin systems. Such a framework may represent the basis to understand the maladaptive mechanisms taking place in neuropsychiatric disorders where the activity of the LHb is altered, and may offer a window to further develop therapeutic strategies.

\section{ACKNOWLEDGMENTS}

We thank C. Bellone for helpful comments on the manuscript. This work is supported by the Ecole de Neuroscience de Paris, Inserm Atip-Avenir and City of Paris (Manuel Mameli). Frank J. Meye is supported by the Fyssen Postdoctoral Fellowship.

\section{REFERENCES}

Aizawa, H., Kobayashi, M., Tanaka, S., Fukai, T., and Okamoto, H. (2012). Molecular characterization of the subnuclei in rat habenula. J. Comp. Neurol. 520, 4051-4066. doi: 10.1002/cne.23167

Andres, K. H., von During, M., and Veh, R. W. (1999). Subnuclear organization of the rat habenular complexes. J. Comp. Neurol. 407, 130-150. doi: 10. 1002/(sici)1096-9861(19990428)407:1<130::aid-cne10>3.0.co;2-8

Araki, M., Mcgeer, P., and Mcgeer, E. (1984). Retrograde HRP tracing combined with a pharmacohistochemical method for GABA transaminase for the identification of presumptive GABAergic projections to the habenula. Brain Res. 304, 271-277. doi: 10.1016/0006-8993(84)90330-5

Barrot, M., Sesack, S. R., Georges, F., Pistis, M., Hong, S., and Jhou, T. C. (2012). Braking dopamine systems: a new GABA master structure for mesolimbic and nigrostriatal functions. J. Neurosci. 32, 14094-14101. doi: 10.1523/jneurosci. 3370-12.2012

Bellone, C., and Luscher, C. (2006). Cocaine triggered AMPA receptor redistribution is reversed in vivo by mGluR-dependent long-term depression. Nat. Neurosci. 9, 636-641. doi: 10.1038/nn1682

Bettler, B., Kaupmann, K., Mosbacher, J., and Gassmann, M. (2004). Molecular structure and physiological functions of GABA(B) receptors. Physiol. Rev. 84, 835-867. doi: 10.1152/physrev.00036.2003

Burnashev, N., Monyer, H., Seeburg, P. H., and Sakmann, B. (1992). Divalent ion permeability of AMPA receptor channels is dominated by the edited form of a single subunit. Neuron 8, 189-198. doi: 10.1016/0896-6273(92)90120-3

Chang, S. Y., and Kim, U. (2004). Ionic mechanism of long-lasting discharges of action potentials triggered by membrane hyperpolarization in the medial lateral habenula. J. Neurosci. 24, 2172-2181. doi: 10.1523/jneurosci.4891-03.2004

Christoph, G. R., Leonzio, R. J., and Wilcox, K. S. (1986). Stimulation of the lateral habenula inhibits dopamine-containing neurons in the substantia nigra and ventral tegmental area of the rat. J. Neurosci. 6, 613-619.

Clem, R. L., and Huganir, R. L. (2010). Calcium-permeable AMPA receptor dynamics mediate fear memory erasure. Science 330, 1108-1112. doi: 10.1126/science. 1195298

Donevan, S. D., and Rogawski, M. A. (1995). Intracellular polyamines mediate inward rectification of $\mathrm{Ca}(2+)$-permeable alpha-amino-3-hydroxy-5-methyl-4isoxazolepropionic acid receptors. Proc. Natl. Acad. Sci. U S A 92, 9298-9302. doi: 10.1073/pnas.92.20.9298

Farrant, M., and Nusser, Z. (2005). Variations on an inhibitory theme: phasic and tonic activation of GABA(A) receptors. Nat. Rev. Neurosci. 6, 215-229. doi: 10. 1038/nrn 1625

Geisler, S., Andres, K. H., and Veh, R. W. (2003). Morphologic and cytochemical criteria for the identification and delineation of individual subnuclei within the lateral habenular complex of the rat. J. Comp. Neurol. 458, 78-97. doi: 10. 1002/cne.10566 
Geisler, S., and Trimble, M. (2008). The lateral habenula: no longer neglected. CNS Spectr. 13, 484-489.

Good, C. H., Wang, H., Chen, Y. H., Mejias-Aponte, C. A., Hoffman, A. F., and Lupica, C. R. (2013). Dopamine D4 receptor excitation of lateral habenula neurons via multiple cellular mechanisms. J. Neurosci. 33, 16853-16864. doi: 10.1523/JNEUROSCI.1844-13.2013

Gruber, C., Kahl, A., Lebenheim, L., Kowski, A., Dittgen, A., and Veh, R. W. (2007). Dopaminergic projections from the VTA substantially contribute to the mesohabenular pathway in the rat. Neurosci. Lett. 427, 165-170. doi: 10.1016/j. neulet.2007.09.016

Herkenham, M., and Nauta, W. J. (1979). Efferent connections of the habenular nuclei in the rat. J. Comp. Neurol. 187, 19-47. doi: 10.1007/978-1-4684-7920$1 \_17$

Hikosaka, O. (2010). The habenula: from stress evasion to value-based decisionmaking. Nat. Rev. Neurosci. 11, 503-513. doi: 10.1038/nrn2866

Hill, D. R. (1985). GABAB receptor modulation of adenylate cyclase activity in rat brain slices. Br. J. Pharmacol. 84, 249-257.

Hnasko, T. S., Hjelmstad, G. O., Fields, H. L., and Edwards, R. H. (2012). Ventral tegmental area glutamate neurons: electrophysiological properties and projections. J. Neurosci. 32, 15076-15085. doi: 10.1523/jneurosci.3128-12.2012

Hollmann, M., Maron, C., and Heinemann, S. (1994). N-glycosylation site tagging suggests a three transmembrane domain topology for the glutamate receptor GluR1. Neuron 13, 1331-1343. doi: 10.1016/0896-6273(94)90419-7

Hong, S., and Hikosaka, O. (2008). The globus pallidus sends reward-related signals to the lateral habenula. Neuron 60, 720-729. doi: 10.1016/j.neuron.2008.09.035

Hortnagl, H., Tasan, R. O., Wieselthaler, A., Kirchmair, E., Sieghart, W., and Sperk, G. (2013). Patterns of mRNA and protein expression for 12 GABAA receptor subunits in the mouse brain. Neuroscience 236, 345-372. doi: 10.1016/j. neuroscience.2013.01.008

Jhou, T. C., Fields, H. L., Baxter, M. G., Saper, C. B., and Holland, P. C. (2009). The rostromedial tegmental nucleus (RMTg), a GABAergic afferent to midbrain dopamine neurons, encodes aversive stimuli and inhibits motor responses. Neuron 61, 786-800. doi: 10.1016/j.neuron.2009.02.001

Jhou, T. C., Good, C. H., Rowley, C. S., Xu, S. P., Wang, H., Burnham, N. W., et al. (2013). Cocaine drives aversive conditioning via delayed activation of dopamine-responsive habenular and midbrain pathways. J. Neurosci. 33, 75017512. doi: 10.1523/jneurosci.3634-12.2013

Kelly, L., Farrant, M., and Cull-Candy, S. G. (2009). Synaptic mGluR activation drives plasticity of calcium-permeable AMPA receptors. Nat. Neurosci. 12, 593601. doi: 10.1038/nn.2309

Keys, A. S., and Ellison, G. D. (1999). Long-term alterations in benzodiazepine, muscarinic and alpha-amino-3-hydroxy-5-methylisoxazole-4-propionic acid (AMPA) receptor density following continuous cocaine administration. Pharmacol. Toxicol. 85, 144-150. doi: 10.1111/j.1600-0773.1999.tb00082.x

Kowski, A. B., Veh, R. W., and Weiss, T. (2009). Dopaminergic activation excites rat lateral habenular neurons in vivo. Neuroscience 161, 1154-1165. doi: 10.1016/j. neuroscience.2009.04.026

Kullmann, D. M., and Lamsa, K. P. (2011). LTP and LTD in cortical GABAergic interneurons: emerging rules and roles. Neuropharmacology 60, 712-719. doi: 10.1016/j.neuropharm.2010.12.020

Lammel, S., Lim, B. K., Ran, C., Huang, K. W., Betley, M. J., Tye, K. M., et al. (2012). Input-specific control of reward and aversion in the ventral tegmental area. Nature 491, 212-217. doi: 10.1038/nature11527

Lamsa, K. P., Heeroma, J. H., Somogyi, P., Rusakov, D. A., and Kullmann, D. M. (2007). Anti-Hebbian long-term potentiation in the hippocampal feedback inhibitory circuit. Science 315, 1262-1266. doi: 10.1126/science.11 37450

Le Roux, N., Cabezas, C., Bohm, U. L., and Poncer, J. C. (2013). Input-specific learning rules at excitatory synapses onto hippocampal parvalbumin-expressing interneurons. J. Physiol. 591, 1809-1822. doi: 10.1113/jphysiol.2012.245852

Li, B., Piriz, J., Mirrione, M., Chung, C., Proulx, C. D., Schulz, D., et al. (2011). Synaptic potentiation onto habenula neurons in the learned helplessness model of depression. Nature 470, 535-539. doi: 10.1038/nature09742

Li, K., Zhou, T., Liao, L., Yang, Z., Wong, C., Henn, F., et al. (2013). $\beta$ CaMKII in lateral habenula mediates core symptoms of depression. Science 341, 1016-1020. doi: 10.1126/science.1240729

Liang, F., Hatanaka, Y., Saito, H., Yamamori, T., and Hashikawa, T. (2000). Differential expression of gamma-aminobutyric acid type $\mathrm{B}$ receptor-1a and - $1 \mathrm{~b}$ mRNA variants in GABA and non-GABAergic neurons of the rat brain. J. Comp. Neurol. 416, 475-495. doi: 10.1002/(sici)1096-9861(20000124)416:4<475::aid-cne5>3 $0 . \operatorname{co} ; 2-\mathrm{v}$

Liu, Y., Fowler, C. D., Young, L. J., Yan, Q., Insel, T. R., and Wang, Z. (2001). Expression and estrogen regulation of brain-derived neurotrophic factor gene and protein in the forebrain of female prairie voles. J. Comp. Neurol. 433, 499514. doi: 10.1002/cne.1156

Lomeli, H., Mosbacher, J., Melcher, T., Hoger, T., Geiger, J. R., Kuner, T., et al. (1994). Control of kinetic properties of AMPA receptor channels by nuclear RNA editing. Science 266, 1709-1713. doi: 10.1126/science.7992055

Lujan, R., and Ciruela, F. (2012). GABAB receptors-associated proteins: potential drug targets in neurological disorders? Curr. Drug Targets 13, 129-144. doi: 10. 2174/138945012798868425

Luscher, C., and Huber, K. M. (2010). Group 1 mGluR-dependent synaptic longterm depression: mechanisms and implications for circuitry and disease. Neuron 65, 445-459. doi: 10.1016/j.neuron.2010.01.016

Luscher, C., Jan, L. Y., Stoffel, M., Malenka, R. C., and Nicoll, R. A. (1997). $\mathrm{G}$ protein-coupled inwardly rectifying $\mathrm{K}+$ channels (GIRKs) mediate postsynaptic but not presynaptic transmitter actions in hippocampal neurons. Neuron 19, 687-695. doi: 10.1016/s0896-6273(00)80381-5

Luscher, C., and Slesinger, P. A. (2010). Emerging roles for G protein-gated inwardly rectifying potassium (GIRK) channels in health and disease. Nat. Rev. Neurosci. 11, 301-315. doi: 10.1038/nrn2834

Mameli, M., Bellone, C., Brown, M. T., and Luscher, C. (2011). Cocaine inverts rules for synaptic plasticity of glutamate transmission in the ventral tegmental area. Nat. Neurosci. 14, 414-416. doi: 10.1038/nn.2763

Mameli, M., Halbout, B., Creton, C., Engblom, D., Parkitna, J. R., Spanagel, R., et al. (2009). Cocaine-evoked synaptic plasticity: persistence in the VTA triggers adaptations in the NAc. Nat. Neurosci. 12, 1036-1041. doi: 10.1038/nn.2367

Margeta-Mitrovic, M., Mitrovic, I., Riley, R. C., Jan, L. Y., and Basbaum, A. I. (1999). Immunohistochemical localization of GABA(B) receptors in the rat central nervous system. J. Comp. Neurol. 405, 299-321. doi: 10.1002/(SICI) 10969861(19990315)405:3<299::AID-CNE2>3.0.CO;2-6

Maroteaux, M., and Mameli, M. (2012). Cocaine evokes projection-specific synaptic plasticity of lateral habenula neurons. J. Neurosci. 32, 12641-12646. doi: 10. 1523/jneurosci.2405-12.2012

Marshall, F. H., Jones, K. A., Kaupmann, K., and Bettler, B. (1999). GABA B receptors - the first 7TM heterodimers. Trends Pharmacol. Sci. 20, 396-399. doi: 10.1016/s0165-6147(99)01383-8

Matsumoto, M., and Hikosaka, O. (2007). Lateral habenula as a source of negative reward signals in dopamine neurons. Nature 447, 1111-1115. doi: 10. 1038/nature 05860

Matsumoto, M., and Hikosaka, O. (2009). Two types of dopamine neuron distinctly convey positive and negative motivational signals. Nature 459, 837-841. doi: 10 . 1038/nature 08028

McCutcheon, J. E., Loweth, J. A., Ford, K. A., Marinelli, M., Wolf, M. E., and Tseng, K. Y. (2011). Group I mGluR activation reverses cocaine-induced accumulation of calcium-permeable AMPA receptors in nucleus accumbens synapses via a protein kinase C-dependent mechanism. J. Neurosci. 31, 14536-14541. doi: 10. 1523/jneurosci.3625-11.2011

Mengod, G., Pompeiano, M., Martinez-Mir, M. I., and Palacios, J. M. (1990). Localization of the mRNA for the 5-HT2 receptor by in situ hybridization histochemistry. Correlation with the distribution of receptor sites. Brain Res. 524, 139-143. doi: 10.1016/0006-8993(90)90502-3

Meshul, C. K., Noguchi, K., Emre, N., and Ellison, G. (1998). Cocaineinduced changes in glutamate and GABA immunolabeling within rat habenula and nucleus accumbens. Synapse 30, 211-220. doi: 10.1002/(sici) 10982396(199810)30:2<211::aid-syn11>3.0.co;2-4

Peyron, C., Tighe, D. K., van den Pol, A. N., de Lecea, L., Heller, H. C., Sutcliffe, J. G., et al. (1998). Neurons containing hypocretin (orexin) project to multiple neuronal systems. J. Neurosci. 18, 9996-10015.

Phillipson, O. T., and Pycock, C. J. (1982). Dopamine neurones of the ventral tegmentum project to both medial and lateral habenula. Some implications for habenular function. Exp. Brain Res. 45, 89-94. doi: 10.1007/bf00 235766

Pirker, S., et al. (2000). GABA(A) receptors: immunocytochemical distribution of 13 subunits in the adult rat brain. Neuroscience 101, 815-850. doi: 10 . 1016/s0306-4522(00)00442-5 
Poller, W. C., et al. (2011). Lateral habenular neurons projecting to rewardprocessing monoaminergic nuclei express hyperpolarization-activated cyclic nucleotid-gated cation channels. Neuroscience 193, 205-216. doi: 10.1016/j. neuroscience.2011.07.013

Rood, B. D., Murray, E. K., Laroche, J., Yang, M. K., Blaustein, J. D., and De Vries, G. J. (2008). Absence of progestin receptors alters distribution of vasopressin fibers but not sexual differentiation of vasopressin system in mice. Neuroscience 154, 911-921. doi: 10.1016/j.neuroscience.2008.03.087

Shabel, S. J., Proulx, C. D., Trias, A., Murphy, R. T., and Malinow, R. (2012). Input to the lateral habenula from the basal ganglia is excitatory, aversive and suppressed by serotonin. Neuron 74, 475-481. doi: 10.1016/j.neuron.2012.02.037

Shen, X., Ruan, X., and Zhao, H. (2012). Stimulation of midbrain dopaminergic structures modifies firing rates of rat lateral habenula neurons. PLoS One 7:e34323. doi: 10.1371/journal.pone.0034323

Smith, Y., Seguela, P., and Parent, A. (1987). Distribution of GABA-immunoreactive neurons in the thalamus of the squirrel monkey (Saimiri sciureus). Neuroscience 22, 579-591. doi: 10.1016/0306-4522(87)90355-1

Solomon, R. L., and Corbit, J. D. (1974). An opponent-process theory of motivation. I. Temporal dynamics of affect. Psychol. Rev. 81, 119-145. doi: 10. 1037/h0036128

Stamatakis, A. M., and Stuber, G. D. (2012). Activation of lateral habenula inputs to the ventral midbrain promotes behavioral avoidance. Nat. Neurosci. 15, 11051107. doi: 10.1038/nn.3145

Wang, R. Y., and Aghajanian, G. K. (1977). Physiological evidence for habenula as major link between forebrain and midbrain raphe. Science 197, 89-91. doi: 10. 1126/science. 194312

Wang, D. G., Gong, N., Luo, B., and Xu, T. L. (2006). Absence of GABA type A signaling in adult medial habenular neurons. Neuroscience 141, 133-141. doi: 10. 1016/j.neuroscience.2006.03.045
Weiss, T., and Veh, R. W. (2011). Morphological and electrophysiological characteristics of neurons within identified subnuclei of the lateral habenula in rat brain slices. Neuroscience 172, 74-93. doi: 10.1016/j.neuroscience.2010. 10.047

Yang, L. M., Yu, L., Jin, H. Z., and Zhao, H. (2013). Substance P receptor antagonist in lateral Habenula improves rat depression-like behaviors. Brain Res. Bull. doi: 10.1016/j.brainresbull.2013.10.007. [Epub ahead of print].

Yin, H. S., Tien, T. W., Li, L., Yang, Y. H., and Lai, C. C. (2012). Amphetamine differentially modifies the expression of monoaminergic and GABAergic synaptic boutons and processes in lateral habenula, dorsal and ventral hippocampal formation. Neurotoxicology 33, 235-245. doi: 10.1016/j.neuro.2011. 10.001

Conflict of Interest Statement: The authors declare that the research was conducted in the absence of any commercial or financial relationships that may represent a potential conflict of interest.

Received: 25 September 2013; paper pending published: 17 October 2013; accepted: 25 November 2013; published online: 16 December 2013.

Citation: Meye FJ, Lecca S, Valentinova K and Mameli M (2013) Synaptic and cellular profile of neurons in the lateral habenula. Front. Hum. Neurosci. 7:860. doi: 10.3389/fnhum.2013.00860

This article was submitted to the journal Frontiers in Human Neuroscience.

Copyright (c) 2013 Meye, Lecca, Valentinova and Mameli. This is an open-access article distributed under the terms of the Creative Commons Attribution License (CC BY). The use, distribution or reproduction in other forums is permitted, provided the original author(s) or licensor are credited and that the original publication in this journal is cited, in accordance with accepted academic practice. No use, distribution or reproduction is permitted which does not comply with these terms. 